were inoculated with the same material. In those animals which had been treated with tuberculin the disease appeared earlier and progressed more rapidly than in the others. In other words, not only was immunity not produced, but the animals were actually rendered more liable to the disease. The clinical observations on man are for the most part in accord with this experiment on guineapigs, especially where the doses given have been very large.

We have therefore in tuberculin a substance which, on the one hand, possesses certain remedial properties, but which, on the other hand, exposes the patient to a series of risks which are of grave importance; and though these risks may be minimised to a certain extent by modifications in the mode of administration and in other ways, yet they must be carefully considered before the treatment is commenced in any given case.

(To be concluded.)

OBSERVATIONS ON THE

TEMPERATURE OF PHTHISICAL PATIENTS IN RELATION TO THE TEMPERATURE OF THE ATMOSPHERE.

By W. S. LAZARUS-BARLOW, B.A., M.B. CANTab., LATE hOUSE PHISICIAN TO THE BROMPTON CONSUMPTION hOSPITAL.

OF the many varied forms of treatment that have from time to time been in vogue for phthisical patients none has received wider attention or has gained credit with greater justice than the climatic. And yet the exact form that this treatment should take has been itself a subject of much difference of opinion. At first a voyage was advocated, llater Madeira, New Zraland, and South Africa were extolled for the good effects of their air. But within the last few years an entire revolution has taken place, and instead of a warm, relaxing climate, clear and bracing air is chosen to which the patient is to be sent. At the same time high elevation above the sea-level is held to be a great advantage, and it is to these combined qualities that the valleys of Davos and the Engadine owe their present reputation in the treatment of consumption. It is, I believe, a generally accepted truth among physicians especially qualified to give an opinion on the subject that consumptive patients enjoy better health in all respects during the winter than during the summer months, and this; too, allowing for the facts that hæmoptysis is more common in hot weather and that the very heat is likely to increase the night sweating. Certainly in lote spring and early summer there apply for admission to hospitals a number of patients who having been under observation and treatment as out. patients for a considerable time nevertheless have such a rapid increase in their symptoms that they are no longer fit to be out-patients, and are easily recognised as suffering under very active or acute phthisis. Now, have these two last facts any thing in common? Is there any cause which operating for the benefit of patients at Davos operates for the benefit of patients in England during the winter months, and ceases to operate or is replaced by a damaging cause during the summer months? In a word, is there any relationship between the temperature of phthisical patients and that of the external air? To determine that question is the object of the present paper. The cases that have been used in this investigation may be included under the head of "acute phthisis," and it will be well to indicate briefly the form of consumption that is meant by that name. At the outset it must be plainly understood that by "acute phthisis" is not meant "acute tuberculosis," with its tubercles widely disaeminated throughout the body. The latter disease is so unlike in its course that of ordinary phthisis, that little good would come of considering it in this connexion. But acute phthisis is often characterised post mortem by the circum. scribed area in which tubercles are found. Perhaps it is only one upper lobe, while the rest of the lungs is almost free. In the affected part tubercles are very thickly studded, and caseate rapidly. Excavation proceeds by strides, andinavery short time the lobe, or possibly the whole lung, may be shelled ont. During life the rapidity of the process may be evidenced by the detection with the microscope of many scarcely altered yellow elastic fibres in the sputa. In fact, this form of phthisis is very closely allied to, if not identical with, the disease formerly called "caseating pneumonia." Night sweats are profuse and anorexia is c smmon; diarrhoea and hæmoptysis are rare (the latter especially so), while the temperature is markedly hectic in character. The prognosis of such cases is bad; of the 100 patients which constibute my weries, twenty-seven died in the hospital, and thirty-two were registered as being "worse" when they left. The patlents are as a rule young, the average of my cases being twenty-six years and ten months.

The grounds upon which this class of case has been chosen for the investigation are three :--1. The hectic nature of the temperatures, of ten showing a difference of from $4^{\circ}$ to $5^{\circ}$ between morning and evening temperatures, will allow a better comparison to be made than where differences are smaller, and also small individual variations do not make so much difference in the general result. 2. There can be no question about the activity of the disease. 3 . There is much greater presumption in favour of careful taking of temperatures when the pyrexia is known to be great than when the temperature is normal or nearly so. Whatever be the individual view as to the advantage or disadvantage of a high temperature per se, everyone agrees that it is an index of the activity of the disease. The higher the temperatkre of the patient, the more active is the disease, and vice versit. Now what is true of the individual is also true of the class to which he belongs, and it may be taken therefore for granted that (cases of acute disease only being under consideration) if of two classes of patients the temperature of one class is lower than that of the other, that class whose temperature is lower is more favourably situated with regard to the disease than that whose temperature is higher. Hence the welfare of the cases under discussion varies inversely as the height of the temperature above normal. To make differences come out in greater contrast, I thought best to confine my inquiry to the two extremes of temperature in the year, and hence chose the following periods of twenty-five days each:- $($ a $)$ 1887: July 14th-Aug. 7th ; (b) 1887-8: Dec. 20th-Jan. 13th; (c) 1888: July 20thAug. 13th ; (d) 1888-9 : Dec. 20th-Jan. 13th. Daring the hot periods the average temperatures for the last fifty years as given in Whitaker's Almanack is $62^{\circ}$, while during the cold periods it is $37^{\circ}$. During the above-mentioned periods there were in the hospital 33 cases, 17 cases, 28 cases, and 22 cases respectively, quite fortuitously 100 cases in all. First, then, with regard to the external temperatures. An average temperature for each period was obtained by simply adding the means of the maxima and minima of each day, and dividing by the number of days (twenty-five) in the period. This method showed that in the periods above $a$ was $3 \cdot 3^{\circ}$ above the average for the last fifty years ; $;^{1} b 8^{\circ}$ below; $c{ }^{\circ} 08^{\circ}$ below $;^{2} d 5^{\circ}$ above. Secondly, with regard to the patients. The male and female cases for each period were set into groups, and the sums of their temperatures on each morning and evening of the period were found. Dividing these sums by the number of cases in a group gave an average temperature, which was charted, corrected to two places of decimals. Next, the same was done for these temperatures as for the external, and hence a single average temperature was also found for all the patients during each of the four periods. They are as below :-

$$
\begin{array}{ccccccc}
\text { Period. } & & & \multicolumn{2}{c}{\text { of patients }} \\
\text { 1887, July-August } \ldots & \ldots & \ldots & \ldots & \ldots & 99 \cdot 680 \\
\text { 1887-8, December-January } & \ldots & \ldots & \ldots & 99 \cdot 090 \\
\text { 1888, July-August _.. } & \ldots & \ldots & \ldots & \ldots & 99 \cdot 516 \\
\text { 1888-9, December-January } & \ldots & \ldots & \ldots & 99 \cdot 734
\end{array}
$$$$
\text { Average temperature }
$$

Comparing the two sets of results, and omitting the winter period of 1888-9 for the moment, we see that the relationship is perfect, and that the order in both classes-patients and atmosphere-is the same:-1. July-August, 1887. 2. July-August, 1888. 3. December, 1888-January, 1889. But the difficulty is the greatest with the temperature of the patients in December-January, 1888-9. These, so far from being lower, actually come out at the top of the series, and, moreover, as there is only $0.009^{\circ}$ between the average of the female and of the male cases during that period, it cannot but be something intrinsic in the temperatures, and not dependent upon error. Now, this difficulty is not insurmountable. Owing to the fact that the whole of the hospital, corridors included, is artificially warmed during winter, it is hardly fair to compare winter and summer

1 Jubilee year, well remembered for the extremely hot and $d r$ summer.

$2 \mathrm{~A}$ cold and wet summer. One is struck by the little difference there is between $a$ and $c$, when one considers the vast difference there seemed to be between the years. 
temperatures inter se, but winter should be compared with winter, and summer with summer. And if this be done, the difficulty entirely vanishes. Glancing back to the two tables, it is seen that-(1) the summer 1887 was hotter than the summer 1888, and the patients' temperatures in the summer 1887 were higher than those of the summer 1888; (2) the winter $1888-9$ was warmer than the winter 1887-8, and the temperatures of the patients in the former period were higher than in the latter period. Further, there is at least a reasonable explanation possible for the fact that in the winter 1888-9 the temperatures of the patients were highest of all. It is seen that the average external temperature of that period was $0.5^{\circ}$ above theaverage of the last fifty years. Now this doesnot tell the whole story. As a reference to the calendar will show, there was a long continuation of very mild weather, but a few days in which the cold was intense, and the minima here entirely swamp in an average the maxima, individually smaller but far more numerous. Now the degrees of frost though they lower the average external temperature will hardly affect that inside an artificially warmed building. Recognising, then, the fact that the period was, as a whole, a very much milder one than would appear by the small amount indicated by the average, my suggestion is as follows : The animul economy in England has been accustomed to cold in winter, but when the weather happens to be particularly mild the animal economy striving to keep balance with it rises but overshoots the mark, and hence gives a higher temperature than we should anticipate. This may seem a fanciful explanation, but there is an exactly analogous example, though in the opposite direction, in the temperatureafter thecrisis of such acute diseases as terminate in that manner. When the crisis comes the temperature tries to fall to normal, but overshoots the mark, and as a consequence remains subnormal for some days. Moreover, in cases of starvation after the giving of nourishment, the temperature, till then subnormal, becomes rapidly raised above normal, and sinks to normal later on; it overshoots the mark, in a word. Speeking broadly, therefore, the temperatures of patients with acute phthisis vary with the external temperature, and consequently their general health is better when the weather is cold.

Now what is true of the greater is also true, though in a lower degree, of the less, and consequently I think we are warranted in assuming that the same holds good with chronic phthisis. As cases of chronic phthisis are those especially for which climatic treatment is advocated, so far as this paper goes it lends support to the Davos and Engadine treatment in preference to that of Madeira and South Africa. As far as actual temperatures on individual days are concerned, I have not satisfied myself that I can trace any definite relationship. Where differences are so small as they are in the variations of human temperatures, it is not likely that anything but a more prolonged change of external temperature would give evidence in the human temperature chart, and consequently the failure of correspondence on definite days need hardly be wondered at.

Note. - At the same time as the above investigation was being carried on observations were also made on the relationship with barometric pressure; but owing to the fact that variations at any given place in England are so small, the results were hardly worth the large amount of trouble entailed in collecting them. Sufficient, however, was done to show that the subject was one which would not prove barren if worked ont for two places (such as Davos and London) having a fair difference of barometric pressure.

Stroud-green, $\mathbf{N}$.

A CASE OF

\section{STRANGULATED RETRO-PERITONEAL HERNIA (MESENTERIC HERNIA OF COOPER).}

By ALFRED G. BARRS, M.D., M.R.C.P., SENIOR ASSISTANT PHYSICIAN TO THE INFIRMARY, LEEDS ; LECTURER ON MATERIA MEDICA IN THE YORKSHIRE COLLEGE, VICTORIA UNIVERSITY.

THE patient, Thomas A-, aged eighteen years, was admitted into the General Infirmary, at Leeds, under the care of the late Mr. McGill, on Oct. 15th, 1890, suffering from a comminuted fracture of the right femur, for which a long external splint and extension by weight and pulley were applied. The case was pursuing a favourable and uneventful course until the morning of Sunday, Oct. 26th, when he complained of intense and continuous pain in the epigastrium, causing him to roll about in bed; later on in the day the pain assumed a burning character, and collapse became marked, the pulse quick and feeble, the skin cold and clammy. Diarrhoea and vomiting set in at the beginning of the pain, and continued to the end. He gradually became worse, and more collapsed, and died at $8 \mathrm{P}$ M. The patient had eaten three green apples and a considerable quantity of grapes on the previous afternoon.

It is scarcely necessary to remark that the conditions found post mortem were entirely unsuspected during life The post-mortem examination was made by myself eighteen hours after death. (A well-grown, well-nourished body; signs of comminuted fracture of the right femur easily demonstrated). The abdomen presented such a striking departure from its natural shape that I at once had a drawing of it made. The walls were extremely tense from pressnre within, which was producing a bulging of the parietes, chiffly or almost entirely involving the lower two-thirds of the abdomen, and so leaving the epigastric: region depressed and empty. The distension had not reen able to overcome the resistance of the rectus ab dominis to such an extent as in other parts of the

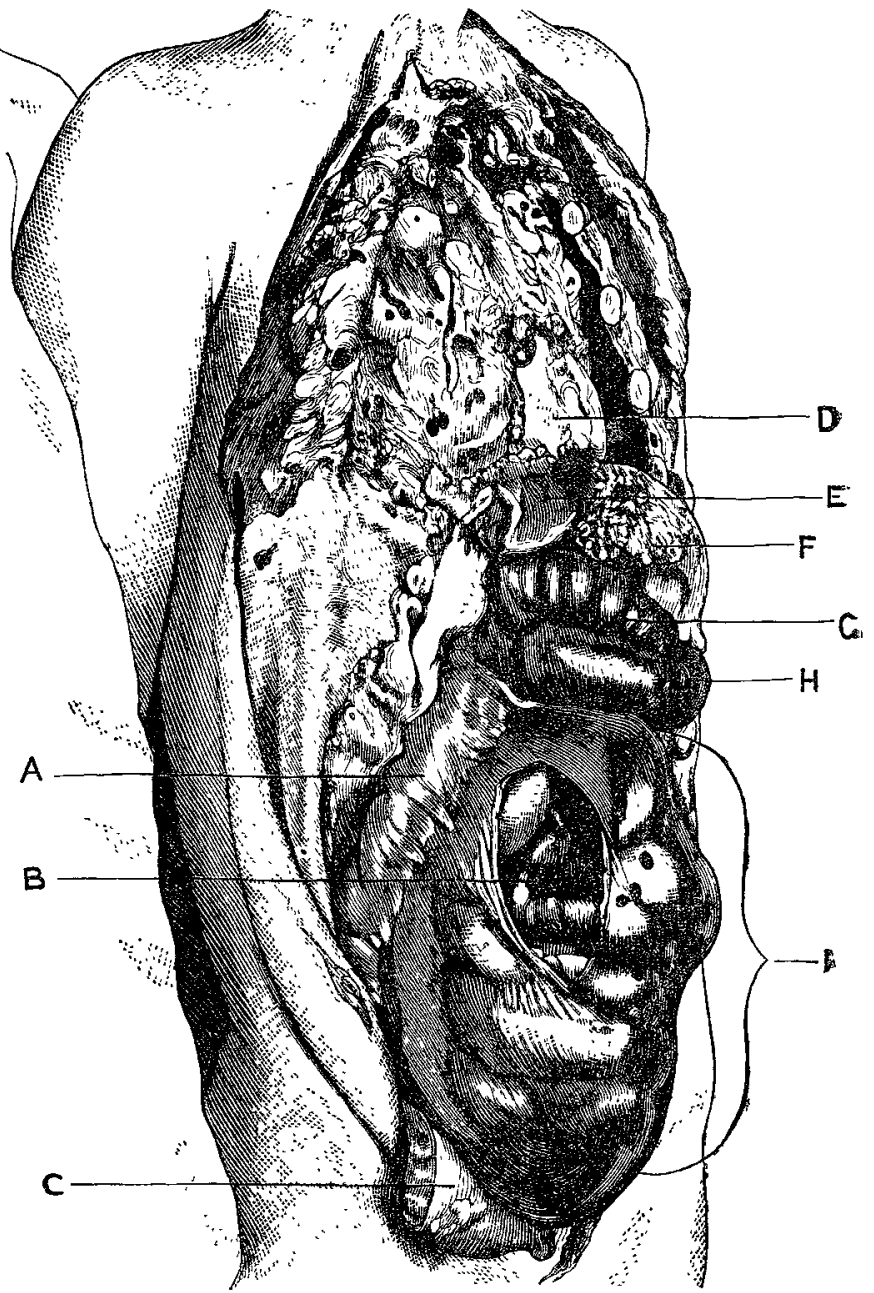

A, Ascending colon in wall of sac. $B$, Artificial opening in the sac. C, Parietal peritoneum. D, Pericardium. E, Left G, Transverse colon. H, Distended jejunum. I, Hernial sac.

abdomen, so that an obvious depression existed in the middle line of the body. The abdomen was tympanitic on percussion in all parts. The whole appearance was not much unlike that presented by the abdomen in pregnancy at term, except for the median depression, and suggested at once the rapidity with which the change had been estab. lished. On opening the body in the ordinary way one at once came upon what appeared to be a second sac of peritoneum, containing apparently the whole of the small intestines, which could be seen distinctly through its walls. This sac corresponded to and was clearly the cause of the unusual shape and distension of the abdomen. It was quite as large as an adult head, perfectly symmetrical, and extremely tense. It appeared to be free towards its upper left and lower limits, so that one's hand could be passed around it in these directions, but attached in all its parts to the right. It could be easily displaced or turned over to theright side, when a largeapertureleading to its interior was at onceexposed, and coils of distended smallintestine began to escape. Its walls were 